\title{
Avaliação da comunicação do posicionamento estratégico: medição do impacto de uma marreta ou análise do envolvimento de uma neblina?
}

\author{
Cayton Darie Mesquetto Mestre em Administração. Fundação Municipal de Ensino de Piracicaba (FUMEP) - Brasil. \\ masquietto@yahoo.com.br \\ DalilaAlvesComế Doutora em Administração. Universidade Metodista de Piracicaba (UNIMEP) - Brasil. \\ dalila.correa@unimep.br \\ Nadia Kaffizinatto Doutora em Administração. Universidade Metodista de Piracicaba (UNIMEP) - Brasil. \\ nkp@nadiamarketing.com.br
}

\begin{abstract}
RESUMO
Pensando a avaliação da comunicação do posicionamento estratégico nas organizações, frente à complexidade dos dias atuais, é viável continuar utilizando os tradicionais modelos de hierarquia de efeitos? Os efeitos da comunicação do posicionamento não podem ser comparados ao impacto de um golpe de marreta e sim a uma neblina que envolve seus potenciais clientes. Porém, os modelos tradicionalmente utilizados para medição dos efeitos da comunicação têm como principais características, a linearidade e unidirecionalidade, se aproximando assim da medição do impacto de uma marreta, mas não dando conta de avaliar as nuances de uma neblina. Nesse sentido, tomando como base a visão sistêmica sobre comunicação, podem-se buscar na cibernética os modelos alternativos para tarefa de analisar o envolvimento da neblina da comunicação do posicionamento. Todavia, em termos de estratégia, os modelos cibernéticos se aproximam mais da escola de configuração do que da escola de posicionamento liderada por Porter. Mas, considerando que a primeira escola enxerga a formação de estratégia como um processo de transformação, se a organização está em movimento seu posicionamento também não seria passível de mudanças? Entretanto, o presente ensaio não pretende encontrar respostas definitivas para essa questão ou outras que surgirão durante o texto, mas sim permitir reflexões aprofundadas sobre o tema em discussão. Ao final, caberá ao leitor decidir se é melhor continuar medindo o impacto de uma marreta ou se aventurar nos mistérios de uma neblina.
\end{abstract}

Palavras-chave: Posicionamento Estratégico. Comunicação. Avaliação de Efeitos.

\section{Evaluation of strategic positioning communication: measurement of the impact of a sledgehammer or analysis of the involvement of a mist}

\begin{abstract}
Considering the evaluation of communication of strategic positioning in organizations, given the complexity of the present day, is it feasible to continue using the traditional models of effects hierarchy? The effects of positioning communication can not be compared to the impact of a sledgehammer blow, but to a haze involving its potential customers. However, the models traditionally used to measure the effects of communication have linearity and unidirectionality, thus approaching the measurement of the impact of a sledgehammer, but not assessing the nuances of a mist. In this sense, based on the systemic view on communication, one can search in cybernetics the alternative models for the task of analyzing the involvement of the fog of the communication of the positioning. However, in terms of strategy, cybernetic models are closer to the configuration school than to the positioning school led by Porter. But considering that the first school sees the formation of strategy as a process of transformation, if the organization is in motion its positioning would also not be changeable? However, the present essay does not aim to find definitive answers to this or other questions that will arise during the text, but rather to allow in-depth reflections on the subject under discussion. In the end it will be up to the reader to decide whether it is better to continue measuring the impact of a sledgehammer or venturing into the mysteries of a fog.
\end{abstract}

Keywords: Strategic Positioning. Communication. Evaluation of Effects. 


\section{INTRODUÇÃO}

Pensando a avaliação da comunicação do posicionamento estratégico nas organizações, frente aos imperativos das questões de codificação/decodificação de mensagens e das tecnologias de informação e comunicação (TICs), é viável continuar utilizando os tradicionais modelos de hierarquia de efeitos com suas características hierárquica e linear?

Segundo Mintzberg, Ahlstrand e Lampel (2000) a questão do posicionamento estratégico ganha força na década de 1980 com a publicação de Estratégia Competitiva de Michael Porter. Porter (2004), ao definir a estratégia competitiva como um conjunto de ações defensivas e ofensivas no sentido de criar uma posição vantajosa para a organização, aponta três posicionamentos genéricos que uma empresa pode adotar: liderança no custo total, diferenciação e enfoque.

Porém no marketing, conforme Galão, Crescitelli e Baccaro (2011), a palavra posicionamento passou a ser conhecida, também nos anos 1980, a partir da definição de Ries e Trout no livro Posicionamento: A Batalha por Sua Mente, ganhando uma conotação de posição distinta, singular, clara e consistente na mente dos consumidores, ou seja, se concentrando fortemente na estratégia de diferenciação.

Combinando essa visão de posicionamento com a noção de Lasswell (1927) de que em um processo de comunicação haverá um emissor que envia mensagens a um receptor por meio de um canal que pode ou não sofrer alterações dos ruídos na mensagem, ganham força na avaliação dos resultados da comunicação do posicionamento os modelos de hierarquia de efeitos (HOE), que, conforme Belch e Belch (2016), normalmente preocupam-se em medir o que é enviado e não os efeitos da comunicação.

Em contraponto à hegemonia da utilização de tais modelos baseados no emissor das mensagens, a partir dos anos 1970, com os trabalhos de Stuart Hall, compilados no Brasil no livro Da Diáspora de 2003, a pesquisa de recepção se torna um novo marco nos estudos de comunicação, de acordo com Costa (2012), focando na questão da codificação/decodificação de mensagens e apontando para um processo de tentativa de dominação e de resistência, mas jamais de total submissão. E, em tempos recentes, colaboram com tal visão os avanços das tecnologias de informação e comunicação que, conforme Seric e Saura (2012), permitiram que as ideias sobre interatividade com os consumidores fossem colocadas em prática, tirando a centralidade da informação do emissor/organização e dando um papel ativo ao receptor/consumidor.

Assim, para uma melhor avaliação dos resultados da comunicação se faz necessária a busca por modelos alternativos aos do tipo HOE. Nesse sentido, a construção de uma alternativa poderia basear-se na cibernética, partindo do princípio de equifinalidade, apresentado por Epstein (1973), e da informação relacional de Maruyama (1973), que se converge no que Morgan (1996) chama de sistemas de relações circulares.

Entretanto, pensando em estratégia, tais sistemas se distanciam da escola de posicionamento liderada por Porter nos anos de 1980 e tem maior convergência com a escola de configuração tendo como base os estudos da Faculdade de Administração da McGill University, que, segundo Mintzberg, Ahlstrand e Lampel (2000), enxerga a formação de estratégia como um processo de transformação.

Mas, esse fato seria um impedimento para avaliar a comunicação de posicionamento a partir deste viés? Contudo, se a organização está em movimento, seu posicionamento também não seria passível de mudanças, ou seja, de transformação?

O presente artigo, ao assumir o formato de ensaio teórico, conforme Meneghetti (2011), não tem o objetivo de dar respostas definitivas sobre as questões levantadas nessa introdução, mas sim orientar os leitores para reflexões mais profundas sobre o tema em discussão.

\section{CONCEITOS DE POSICIONAMENTO}

É "chover no molhado" falar sobre as dificuldades que as organizações enfrentam para conquistarem uma posição competitiva sustentável levando em conta o ambiente altamente dinâmico e mutável que temos na atualidade. Porém, não podemos negar que tal cenário faz do posicionamento um tema essencial e estratégico para qualquer empresa que deseje ser competitiva nos dias de hoje. 
De forma geral, conforme Galão, Crescitelli e Baccaro (2011), posicionamento pode ser definido como o desenvolvimento da oferta e da imagem de determinada organização para ocupar uma posição distinta e significativa nas mentes dos consumidores, ou seja, é a forma como a empresa deseja que seu público-alvo a perceba.

E é exatamente por trabalhar com a percepção do consumidor que esse conceito pode ser considerado uma decisão estratégica, já que pode influenciar o processo de decisão de compra e, consequentemente, os resultados da organização.

Segundo Mintzberg, Ahlstrand e Lampel (2000), a questão do posicionamento estratégico passou a ganhar força na década de 1980 com a publicação de Estratégia Competitiva de Michael Porter. Porter (2004), ao definir a estratégia competitiva como um conjunto de ações defensivas e ofensivas no sentido de criar uma posição vantajosa para a organização, aponta três posicionamentos genéricos que uma empresa pode adotar: liderança no custo total, diferenciação e enfoque, resultado da combinação do escopo de determinada empresa com dois tipos básicos de vantagem competitiva que tal empresa pode possuir: baixo custo ou diferenciação.

Entretanto, através de uma visão polêmica, Porter (2004) entende que uma empresa precisa necessariamente escolher uma das estratégias competitivas para não correr o risco de ficar atolada no meio do cenário competitivo com desempenhos abaixo da média, ou seja, as organizações precisam fazer uma opção única para obter vantagem competitiva.

Muitos foram aqueles que questionaram essa noção de Porter, segundo Mintzberg, Ahlstrand e Lampel (2000), uma vez que uma especialização estratégica poderia causar inflexibilidade, além de estreitar a visão de uma organização. Também se deve considerar que tal concepção estreita não dá conta de explicar o sucesso de empresas da moda, por exemplo, que produzem peças diferenciadas com baixo custo e em grande escala, ou, ainda, as estratégias bem-sucedidas de tomada da dianteira, em que empresas entram em um mercado como produtoras de baixo custo e depois se diferenciam para conquistar maior participação, comum no setor de cosméticos.

Focando na área de marketing, conforme Galão, Crescitelli e Baccaro (2011), a palavra posicionamento passou a ser conhecida, também nos anos 1980, a partir da definição de Ries e Trout no livro Posicionamento: A Batalha por Sua Mente, ganhando uma conotação de posição distinta, singular, clara e consistente na mente dos consumidores, ou seja, se concentrando fortemente na estratégia de diferenciação, porém nada impede que tal diferencial se dê através de preços baixos, advindos de uma estratégia de baixo custo.

Ou seja, embora aparentemente a visão de posicionamento do marketing seja mais restrita que a de Porter, ao tratá-lo somente como diferenciação. Na prática ela é mais abrangente, já que dentro de um guardachuva se colocam diferentes estratégias, inclusive sendo possível a combinação entre elas.

Nesse sentido, de acordo com Hooley, Saunders e Piercy (2011), o posicionamento passa pela compreensão, por parte da empresa, de como os clientes compram ofertas alternativas no mercado, combinada com a definição de estratégias que demonstrem ao cliente a forma como sua oferta difere em aspectos importantes no que diz respeito ao oferecido pelos concorrentes.

Porém, conforme Ries e Trout (2001), em essência posicionamento não é o que você faz com um produto, mas sim o que você faz com a mente do seu cliente. Isso é, o produto é posicionado na mente do cliente. Assim, não se trata de criar algo novo e diferente, mas sim de manipular aquilo que já está dentro da mente, reatando antigas conexões, demonstrando que você oferece aquilo que ele procura.

Dessa forma a mente do consumidor se torna um ponto essencial para os profissionais de marketing na definição do posicionamento. Mas deve-se levar em conta que cada consumidor terá percepções e reações diferentes para as mais diversas ações das empresas.

Sendo assim, tomando por base a visão de Ries e Trout (2001), os efeitos da comunicação do posicionamento não podem ser comparados ao impacto de um golpe de marreta, que com uma única estratégia irá alcançar todos os potenciais clientes. Eles se comparam mais a uma neblina que envolve seus potenciais clientes, combinando diferentes estratégias para ter um alcance cada vez maior.

Mas, como avaliar e mensurar os efeitos da comunicação do posicionamento levando em conta o exposto até aqui? 


\section{AVALIAÇÃO DOS EFEITOS DA COMUNICAÇÃO DO POSICIONAMENTO}

Antes de avaliar os efeitos de qualquer tipo de comunicação se faz necessário saber como a comunicação é concebida. Nesse sentido, por volta da década de 1940, Harold Lasswell, sustentado por sua obra de 1927, propôs um modelo de comunicação que permitia a análise da interação de todos os elementos do processo: quem diz o que, em que canal, a quem e com que efeitos (LASSWELL, 1927). Segundo Beltrán (1980), essa definição de processo de comunicação se manteve amplamente aceita por muito tempo baseando-se na teoria clássica de estímulo-reposta da psicologia clássica.

A evolução desse modelo se deu com a preocupação com os efeitos causados por qualquer processo de comunicação. Entretanto, apesar da evolução dos modelos de processo de comunicação, alguns elementos se mantiveram constantes. Ou seja, há sempre um emissor que envia mensagens a um receptor por meio de um canal que pode ou não sofrer alterações dos ruídos na mensagem.

Considerando essa concepção de processo de comunicação somada ao interesse primordial das organizações em obter bons resultados em termos de vendas e volumes, uma pergunta passa a atormentar as empresas em geral: como medir os efeitos de um programa de comunicação? Essa mesma pergunta vale para a comunicação do posicionamento.

Neste sentido, Belch e Belch (2016) consideram que a medição dos efeitos da comunicação deve avaliar o comportamento de compra real, entendendo este como atividade mensurável pelo cliente, ou seja, devem-se medir atitudes em relação a algo que foi comunicado. Assim, a medição dos efeitos de comunicação se torna uma tarefa tênue, repleta de dificuldades.

Em um esforço para tentar avaliar o impacto e os efeitos da comunicação, mais especificamente da publicidade, Schultz e Barnes (2001) salientam que em 1961 Lavidge e Steiner desenvolveram o modelo de uma hierarquia de efeitos que buscava ilustrar como os consumidores poderiam reagir à exposição de determinada publicidade.

No modelo de Lavidge e Steiner (1961) os consumidores se moviam em um contínuo de atitudes, a partir da exposição a uma comunicação, passando por sete etapas, iniciando-se no desconhecimento da existência de determinado produto e finalizava-se na efetiva aquisição do produto. Colley (1976) propôs um modelo semelhante definindo cinco estágios atitudinais do consumidor, porém definindo metas publicitárias para comparar os resultados medidos em cada estágio, ficando conhecido como abordagem DAGMAR.

A partir de então, ganham força na avaliação dos resultados da comunicação do posicionamento os modelos de hierarquia de efeitos (HOE), que assumem novas versões e imperam até os dias atuais. Conforme Belch e Belch (2016), tais modelos normalmente preocupam-se em medir o que é enviado e não os efeitos da comunicação propriamente ditos, assumindo as características de serem lineares e unidirecionais, partindo do emissor ao receptor.

Assim, esses modelos parecem ideais para avaliar os efeitos do impacto de uma marreta em uma superfície. Porém, será que as nuances de uma neblina envolvem todos os pontos de forma uniforme, com uma mesma densidade, e assumem uma mesma direção?

\section{AS QUESTÕES DE CODIFICAÇÃO/DECODIFICAÇÃO E DAS TECNOLOGIAS DE INFORMAÇÃO E COMUNICAÇÃO}

Em contraponto à hegemonia da utilização de modelos empíricos positivistas baseados no emissor das mensagens, a partir dos anos 1970, com os trabalhos de Stuart Hall, passa a ganhar força a pesquisa de recepção focando na questão da codificação/decodificação de mensagens.

Hall (2003) opõe-se a uma certa unilinearidade implícita nos modelos de hierarquia de efeitos com fluxo unidirecional, que consideram a comunicação perfeita, baseada em um significado perfeitamente transparente que o receptor pode ou não entender, cabendo ao emissor procurar saber quais os obstáculos para a perfeita transmissão do sentido de sua mensagem. 
Para Hall (2003), a mensagem é uma estrutura complexa de significados, fazendo com que a recepção não seja algo aberto e perfeitamente transparente, ou seja, a cadeia comunicativa não opera de forma unilinear. Além disso, o autor apresenta a noção de que o significado de uma mensagem não é fixo, possuindo várias camadas, sendo sempre multirreferencial.

Nesse sentido Costa (2012), baseando-se nos estudos de Hall, apresenta três posições hipotéticas de interpretação de mensagens por parte do receptor: i) uma posição dominante, quando o sentido da mensagem é decodificado conforme as referências utilizadas pelo emissor; ii) uma posição negociada, quando o sentido da mensagem entra em negociação com as referências condicionais particulares dos receptores; iii) uma posição de oposição, quando o receptor entende a proposta do emissor, mas se contrapõe a ela a partir de uma estrutura de referência alternativa.

Assim, os efeitos da comunicação do posicionamento podem tomar densidades e caminhos diferentes, como uma neblina que depende do contato do ar quente com uma superfície fria para se formar, mas se movimenta conforme a velocidade e a direção dos ventos, que podem se alterar de uma hora para outra.

Partindo dessa ideia, rompe-se também com o que Brittos (1998) chama de análises apocalípticas, que veem o receptor como um ser indefeso e apático diante do poder indefensável da mídia a serviço do emissor. Assim, assume-se o bom senso de que a sociedade não é só mídia, e, assim, os efeitos da comunicação do posicionamento não dependem só da vontade do emissor que contrata seus serviços.

Toda esta visão é exacerbada, em tempos recentes, pelos avanços das tecnologias de informação e comunicação (TICS) que, conforme Seric e Saura (2012) permitiram que as ideias sobre interatividade com os consumidores fossem colocadas em prática, tirando definitivamente a centralidade da informação do emissor/organização e consolidando a possibilidade de papel ativo ao receptor/consumidor.

Segundo Schultz e Barnes (2001), as empresas controlaram por muito tempo a maior parte da tecnologia de informação e com isso detinham o controle do mercado, enquanto os consumidores só reagiam, mas não controlavam os mercados em que viviam e operavam. No entanto, atualmente, percebe-se um deslocamento de poder, no mercado, da empresa para o consumidor ou cliente, tendo em vista o deslocamento da informação.

Nesse sentido, a principal diferença entre o mercado atual e o tradicional é ele ser interativo, isto é, a informação e o conhecimento fluem em mão dupla, ou seja, da empresa para o consumidor e também do consumidor para a empresa. Assim, para Schultz e Barnes (2001), o controle do mercado passa a ser partilhado com os clientes e consumidores, o que é explicado pelo maior acesso à informação e ao conhecimento por parte dos clientes. Com isso, os consumidores podem determinar o que desejam comprar, procurar todas as fontes disponíveis e comparar preços e alternativas quando, onde e usando o método que queiram.

E, conforme Seric e Saura (2012), tal interatividade também acarreta que a gestão de todas as fontes de informações que chegam ao cliente passe a ser impossível, pois hoje em dia o próprio cliente decide que informação quer receber, além de apresentar suas opiniões em inúmeros meios de comunicação, não aceitando a informação que a empresa deseja passar.

Portanto, embora o ideal seja que a empresa estabeleça e comunique o seu posicionamento para 0 consumidor, Rotta et al. (2012) lembram que isso pode acontecer também por acaso, através da comunicação entre consumidores. Assim, nem sempre as percepções do consumidor coincidem com a estratégia de posicionamento que a organização planejou.

Nesse cenário, Belch e Belch (2016) apontam que para avaliar os efeitos da comunicação é necessário entender o processo de respostas que os consumidores percorrem até a compra, ou seja, a questão é como medir o impacto dos contatos da mensagem da empresa com os clientes, sendo que isso só é possível invertendo o processo de medição, partindo-se do cliente, e não mais da empresa, para melhor compreender a decisão de compra.

Mas, levando em consideração toda a complexidade que envolve o processo de comunicação, como visto até aqui, e entendendo que medir o impacto de uma marreta é muito mais fácil que analisar o envolvimento de uma neblina, existem alternativas concretas para a avaliação dos efeitos da comunicação do posicionamento? 


\section{ALTERNATIVAS DE AVALIAÇÃO DOS EFEITOS DA COMUNICAÇÃO DO POSICIONAMENTO BASEADAS NA CIBERNÉTICA}

Luhmann (2006) define complexidade como a totalidade dos possíveis acontecimentos e das circunstâncias, sendo um processo que induz obrigatoriamente à seleção. Segundo Curvello e Scroferneker (2008) a base da Teoria dos Sistemas Sociais de Luhmann está na redução da complexidade por meio da diferença dos sistemas com relação ao entorno. Sendo que ao reduzirem complexidade, as organizações como sistemas também constroem sua própria complexidade.

Para Luhmann (2006), esse processo seletivo de redução de complexidade se dá por decisões que se realizam por eventos passageiros e contingentes. Na interpretação de Curvello e Scroferneker (2008), isso significa que os eventos se sobrepõem de tal forma que sempre se está decidindo de uma maneira nova sobre um mesmo tema. Ou seja, o sistema opera em constante seleção, em um fluxo contínuo e autorreferencial, em que as seleções geram decisões, que geram novas seleções para novas decisões.

Pensando na decisão de posicionamento por parte da empresa, ela selecionará os diferenciais que posicionarão seu produto no mercado, a decisão tomada a partir de tal seleção influenciará nas seleções dos consumidores para a tomada de decisão de compra, que por sua vez dará condições para a empresa decidir em manter o posicionamento ou reposicionar seu produto.

Nesse contexto, o conceito de comunicação é central na teoria de Luhmann (2006), pois se torna um dispositivo fundamental da dinâmica evolutiva dos sistemas sociais, uma vez que se trata de um processo de seleções e, como já mencionado, é pela seleção que se opera o processo de redução de complexidade na relação com o ambiente.

Conforme Curvello (2008), a tese central de Luhmann é de que a comunicação é improvável, uma vez que há uma série de obstáculos e dificuldades que precisam ser superados para que se realize. Porém, embora improvável, experimentamos e praticamos a comunicação diariamente, mesmo de forma imperfeita, pois ela é essencial, inclusive para as tomadas de decisão referentes a posicionamento e compra.

Seguindo a visão de Luhmann (2006), a comunicação surge como um dispositivo cibernético destinado a normalizar as relações sistema-meio. Assim, talvez através da cibernética possamos encontrar alternativas para a avaliação dos efeitos da comunicação do posicionamento, considerando toda sua complexidade.

Nesse sentido, podemos citar o princípio de equifinalidade, apresentado por Epstein (1973), que mostra que os mesmos resultados finais podem ser atingidos por meio de diferentes trajetórias, deixando de lado a determinação de linhas únicas para assumir o formato de um reticulado com várias trajetórias possíveis. Assim, através de um processo de aprendizagem de tentativa e erro vai se conhecendo os melhores percursos, utilizando-se de um dispositivo de feedback durante a caminhada, diminuindo as probabilidades de maus caminhos.

Assumindo essa linha de raciocínio somada à noção de informação relacional de Maruyama (1973), que focaliza o papel do feedback positivo e negativo no delineamento da dinâmica e da forma dos sistemas, Morgan (1996) apresenta o conceito de sistemas de relações circulares, substituindo as linhas e a ideia de causalidade mecânica, claramente visualizadas nas características lineares e unidirecionais dos modelos de hierarquia de efeitos, pelos círculos e pela ideia de mútua casualidade, dando pistas para a construção de modelos alternativos para avaliação dos efeitos da comunicação.

Seguindo tais pistas, podem-se encontrar formas de analisar a neblina, que é o efeito da comunicação do posicionamento, considerando as relações entre os elementos e efeitos que dão a ela diferentes direções e densidades, envolvendo de forma diversa cada ponto de medição.

Entretanto, pensando em estratégia, tais sistemas se ap roximam mais da escola de configuração que enxerga a formação de estratégia como um processo de transformação do que da escola de posicionamento liderada por Porter. Sendo assim, seria viável estudar o efeito da comunicação do posicionamento através dessa ótica? 


\section{ESCOLA DA CONFIGURAÇÃO}

Toda a complexidade até aqui apresentada configura uma nova dimensão da comunicação organizacional. Segundo Cardoso (2006), tal dimensão transparece que o processo de comunicação, representado por modelos homogeneizados, verticalizados e com ênfase na instrumentalidade, não é a melhor maneira para responder aos desafios da gestão estratégica das organizações nos tempos atuais.

Porém, o autor ao defender essa tese inclui entre os modelos que não dão conta da complexidade aqueles baseados na cibernética e nos sistemas, defendendo que é necessário ultrapassar fórmulas que estejam comprometidas com a racionalidade instrumentalizada e o monopólio da verdade. Nesse sentido, se deveriam buscar formas de colocar o ser humano em pauta, sem desprezar a subjetividade e a afetividade, enxergando a organização como resultado de um processo dialógico com o meio ambiente.

Tal visão tem como base a ideia defendida por Genelot (2001) de que o significado da comunicação é dado pelo receptor, considerando que o essencial no processo de comunicação se dá sempre no universo simbólico e social do receptor da mensagem, construído por meio de atividades cognitivas, do ambiente social e das estruturas organizacionais.

Nesse sentido, Cardoso (2006) apresenta a posição de Habermas de que o conceito cibernético não permite a constituição de significados da interação dialógica ao serem previamente estabelecidos e internalizados pelos atores que constituem o sistema, não enxergando a praticabilidade do diálogo no ambiente sistêmico representado na teoria de Luhmann, acreditando que o diálogo decorre da ação comunicativa entre atores sociais, o que levaria a imaginar que a medição dos efeitos da comunicação do posicionamento só seria possível avaliando os diálogos caso a caso.

Entretanto, entendendo que a escola da configuração tem a cibernética como um de seus fundamentos, é possível avistar uma possibilidade de utilizar modelos para avaliar efeitos da comunicação do posicionamento, mesmo considerando o cenário complexo em que vivemos.

Conforme Mintzberg, Ahlstrand e Lampel (2000) a escola da configuração, baseada nos estudos da Faculdade de Administração da McGill University, descreve o estado da organização e o seu contexto como configuração e o processo de produzir estratégia como transformação. Assim, a organização ao adotar certo estado, faz com que o processo de produzir a estratégia torne-se um processo de passagem de um estado para outro, sendo a transformação uma consequência da configuração.

Dentre muitos estudos que utilizam dessa concepção de estratégia, podemos citar Miles e Snow (1978) que desenvolveram um modelo do processo estratégico pelo qual uma organização continuamente ajusta-se ao seu ambiente. Esse modelo, denominado de ciclo adaptativo, demonstra os principais problemas que a organização tem que resolver para conseguir uma posição vantajosa em determinado ambiente, esclarecendo que a abordagem é uma tentativa de explicação do processo estratégico, considerando que a adaptação organizacional é altamente complexa e mutante.

Nesse sentido, o conceito de escolha estratégica, apresentado por Miles e Snow (1978), sustenta que a efetividade da adaptação depende da percepção que a organização tem das condições ambientais e das decisões que toma para se ajustar nessas condições. Assim, vai ao encontro da visão de Genelot (2001) que se trata de administrar na complexidade e não administrar a complexidade, pois o imprevisto estará sempre presente, solicitando escolhas e adaptações.

Para Degenhardt e Mañas (2005) a organização estará sempre ao sabor de novos fatos e mudanças, que exigirão reconfigurações estratégicas. Essas mudanças pedem uma conceituação, que modelos baseados na cibernética, como o de Miles e Snow, são capazes de fornecer por ser suficientemente abrangentes para captar a complexidade do mundo moderno.

Assim, sendo estratégica a decisão do posicionamento por parte de uma organização, modelos baseados na cibernética não poderiam ser boas opções para a avaliação de seus efeitos?

Pensando nas escolas estratégicas, Degenhardt e Mañas (2005) apontam que para a escola da configuração a chave do gerenciamento estratégico é sustentar uma estabilidade passageira, reconhecendo a necessidade da transformação, sendo capaz de gerenciar esse processo. Na fase de estabilidade a organização pode adotar outras formulações estratégicas, como as da escola do posicionamento. 
Dessa forma, não haveria impedimentos utilizar modelos focados na tradição da escola da configuração para avaliar os efeitos da comunicação do posicionamento. Pois, como uma neblina que se transforma dependendo das mudanças ocorridas nos elementos que a formam, o posicionamento também se renova com as mudanças do ambiente da organização.

Ou seja, se a organização está em movimento seu posicionamento também não seria passível de transformação?

\section{CONSIDERAÇÕES FINAIS}

Conforme Meneghetti (2011), no ensaio, é mais relevante estabelecer as dúvidas certas do que chegar às afirmações tidas como verdadeiras, não sendo preciso uma conclusão no sentido tradicional, uma vez que cada parte é uma conclusão por si mesma, ao questionar e refletir sobre tais questionamentos.

Nesse sentido, o presente ensaio teve como objetivo aprofundar as reflexões sobre a viabilidade de continuar utilizando os hegemônicos e tradicionais modelos de hierarquia de efeitos com suas características hierárquica e linear para avaliar a comunicação do posicionamento estratégico nas organizações, frente aos imperativos das questões de codificação/decodificação de mensagens e das tecnologias de informação e comunicação.

Porém, não se buscou aqui esgotar as discussões sobre o assunto e, muito menos, apresentar uma afirmação absoluta de como avaliar os efeitos da comunicação do posicionamento. Assim, foram ap resentados os modelos tradicionais e suas características, bem como, alguns fatores críticos que levam a questionar o seu uso. Posteriormente, foram discutidas as bases para a elaboração de modelos alternativos, inclusive também relatando a existência de críticas a essas alternativas, levando em consideração as dificuldades impostas pela complexidade que envolve $o$ assunto.

Entretanto, deve-se levar em conta que, mais difícil e complexo que seja encontrar modelos e ferramentas ideais para avaliar os efeitos do posicionamento, as organizações só investirão naquilo que elas possam medir o retorno. Portanto, quando se investir em planos para comunicar o posicionamento da empresa ou de seus produtos será exigida uma forma de avaliar os resultados desse plano. Assim, continuará havendo a busca por modelos que possam cada vez mais se aproximar de uma forma viável de se avaliar os efeitos da comunicação do posicionamento.

Como autores, continuaremos pesquisando informações sobre 0 assunto, analisando a viabilidade dos modelos já existentes e buscando colocar em prática alternativas de avaliação. E você leitor, continuará medindo o impacto da marreta ou irá se aventurar nos mistérios da neblina?

\section{REFERÊNCIAS}

BELCH, G. E.; BELCH, M. A. Evaluating the effectiveness of elements of integrated marketing communications: a review of research. Skap Journal, Bratislava (Eslováquia), v. 4, n. 1, p. 185-204, jun. 2016.

BELTRÁN, L. R. Farewell to Aristotle: horizontal communication. Communication, Nova York (EUA), v. 5, n. 1, p. 5-41, 1980.

BRITTOS, V. C. Comunicação e cultura: o processo de recepção. In: LAURINDO, R.; TEIXEIRA, T. (org.). Temas em comunicação e cultura contemporâneas. Salvador: Graphite, 1998, p. 129-139.

CARDOSO, 0. O. Comunicação empresarial versus comunicação organizacional: novos desafios teóricos. Revista de Administração Pública, Rio de Janeiro, v. 40, n. 6, p. 1123-1144, dez. 2006.

COLLEY, R. H. DAGMAR: sistema de defininição de objetivos publicitários para medir a eficiência da propaganda. São Paulo: Pioneira, 1976. 
COSTA, J. H. Stuart Hall e o modelo "encoding and decoding": por uma compreensão plural da recepção. Espaço Acadêmico, Maringá, v. 12, n. 136, p. 111-121, set. 2012.

CURVELLO, J . J . A. Uma revisão crítica dos paradigmas clássicos da comunicação e de seus impactos nas organizações. Comunicologia, Braśilia, v. 1, n. 1, p. 10-28, jan./dez. 2008.

CURVELLO. J. J . A.; SCROFERNEKER, C. M. A. A comunicação e as organizações como sistemas complexos: uma análise a partir das perspectivas de Niklas Luhmann e Edgar Morin. E-compós, Brasília, v. 11, n. 3, p. 1-16, set./dez. 2008.

DEGENHARDT, V. W.; MAÑAS, A. V. O modelo de estratégia competitiva de Miles \& Snow e a complexidade conforme Genelot. In: SEM INÁRIOS DE ADMINISTRAÇÃO FEA/USP (SEMEAD), 8., 2005, São Paulo. Anais eletrônicos [...]. São Paulo: USP, 2005. Disponível em: http://sistema.semead.com.br/8semead/resultado/trabalhosPDF/138.pdf. Acesso em: 9 maio 2017.

EPSTEIN, I. Introdução. In: EPSTEIN, I (org.). Cibernética e comunicação. São Paulo: Cultrix, 1973. p. 9-44.

GALÃO, F. P.; CRESCITELLI, E.; BACCARO, T. A. Comunicação integrada de marketing: uma ferramenta do posicionamento estratégico? UNOPAR Científica, Ciências J urídicas e Empresariais, Londrina, v. 12, n. 1, p. 85-91, mar. 2011.

GENELOT, D. Manager dans la complexité: reflexions à l'usage des dirigents. 3. ed. Paris: Insep Consulting, 2001.

HALL, S. Da Diáspora: identidades e mediações culturais. Belo Horizonte: Editora UFMG, 2003.

HOOLEY, G.J .; SAUNDERS, J.A.; PIERCY, N.F. Estratégia de marketing e posicionamento competitivo . 4. ed. São Paulo: Prentice Hall, 2011.

LASSWELL, H. Propaganda technique in the World War. London: Kegan Paul, Trench, Trubner \& Co, Ltd,1927.

LAVIDGE, R. J.; STEINER, G. A. A model for predictive measurements of advertising effectiveness. Journal of Marketing, Chicago (EUA), v. 25. n. 6, p. 59-62, out. 1961.

LUHMANN, N. A improbabilidade da comunicação. 4. ed. Lisboa: Vega, 2006.

MARUYAMA, M. Metaorganização da informação. In: EPSTEIN, I (org.). Cibernética e comunicação. São Paulo: Cultrix, 1973. p. 150-164.

MENEGHETTI, F. K. O que é ensaio teórico? RAC, Curitiba, v. 15, n. 2, p. 320-332, mar./abr. 2011.

MILES, R. E.; SNOW, C. C. Organizational Strategy, Structure, and Process. New York: McGraw-Hill, 1978.

MINTZBERG, H; AHLSTRAND, B.; LAMPEL, J. Safári de estratégia: um roteiro pela selva do planejamento estratégico. Porto Alegre: Bookman, 2000.

MORGAN, G. Imagens da organização. São Paulo: Atlas, 1996.

PORTER, M. E. Estratégia competitiva: técnicas para análise de indústrias e da concorrência. 2. ed. Rio de Janeiro: Elsevier, 2004.

RIES, A.; TROUT, J. Posicionamento: a batalha pela sua mente. 8. ed. São Paulo: Pioneira Thomson Learning, 2001.

ROTTA V.P. et al. Redes sociais virtuais e planejamento de marketing: um estudo multicasos. Revista de

Administração da UNIMEP, Piracicaba, v. 10, n. 2, p. 128-154, maio/ago. 2012. 
SERIC, M.; SAURA, I. G. La investigación en torno a la comunicación integrada de marketing: una revisión. Cuadernos de Administración, Bogotá (Colômbia), v. 25, n. 44, p. 63-92, jun. 2012.

SCHULTZ, D. E.; BARNES, B. E. Campanhas estratégicas de comunicação de marca. Rio de Janeiro: Qualitymark, 2001. 